\title{
Tracheal Intubation with Different Doses of Propofol - Haemodynamic Changes
}

\author{
Sudhir N. ${ }^{1}$, Satheedevi P. ${ }^{2}$, Sunilkumar T.S. ${ }^{3}$, Elizabeth Joseph ${ }^{4}$ \\ 1,2,3,4 Department of Anaesthesiology, Government Medical College, Thrissur, Kerala, India.
}

\section{ABSTRACT}

\section{BACKGROUND}

Stress response to intubation produces marked hemodynamic changes during direct laryngoscopy using muscle relaxants. Since attenuation of hemodynamic response to laryngoscopy and tracheal intubation leads to better outcomes, a method for providing good intubating conditions rapidly without using muscle relaxants is being sought. The objective of the present study was to compare the hemodynamic changes occurring while intubating with 2 different doses of propofol.

\section{METHODS}

We compared heart rate, systolic blood pressure, diastolic pressure and mean arterial pressure changes during tracheal intubation with 2 different propofol doses without using muscle relaxants. Intravenous fentanyl inhibits the sympathetic nervous response to direct laryngoscopy and tracheal intubation in both groups of patients and acts as pre-emptive analgesia.

\section{RESULTS}

Comparison of the hemodynamic parameters revealed no statistically significant differences between the low dose propofol (PL) and high dose propofol (PH) groups with regard to heart rate or blood pressure changes at similar intervals postintubation. Both patient groups showed blood pressure fall along with a reflex increase in heart rate at 1 minute to 5 minutes post-intubation, returning to nearbaseline values 10 minutes post-intubation. None of these changes was either clinically detrimental or produced incidents of desaturation or arrhythmias in any study patient.

\section{CONCLUSIONS}

Low dose propofol may be useful in elderly or mildly hypovolemic patients, intolerant to a higher drug dosage whereas, the higher propofol dose may be particularly useful in the adult with a higher muscle mass in situations where muscle relaxant is to be restricted or avoided.
Corresponding Author: Dr. Sudhir N., Assistant Professor, Department of Anaesthesiology, Government Medical College, Thrissur-680596, Kerala, India. E-mail: jyothypsudhir@gmail.com

DOI: $10.14260 /$ jemds $/ 2022 / 5$

How to Cite This Article:

Sudhir N, Satheedevi P, Sunilkumar TS, et al. Tracheal intubation with different doses of propofol - haemodynamic changes. $J$ Evolution Med Dent Sci 2022;11(01):21-26, DOI: $10.14260 /$ jemds $/ 2022 / 5$

Submission 18-12-2021,

Peer Review 24-12-2021,

Acceptance 06-01-2022,

Published 11-01-2022.

Copyright (C) 2022 Sudhir N. et al. This is an open access article distributed under Creative Commons Attribution License [Attribution 4.0 International (CC BY 4.0)]

\section{KEY WORDS}

Tracheal Intubation, Hemodynamic Changes, Different Doses Propofol. 


\section{BACKGROUND}

Airway manipulation by the anaesthesiologist during attempted endotracheal intubation of a patient produces inadvertent stimulation of pharyngeal and laryngotracheal nociceptors resulting in profound hemodynamic stress response. This is particularly deleterious to the patient with a poor cardiac reserve or with other comorbidities. Though modern muscle relaxants provide excellent intubating conditions, they do not produce a reduction in intubation stress response. Further, all of them have undesirable side effects: hypotension, dysrhythmias, bronchoconstriction, residual paralysis and long term muscle weakness, histamine release, allergic reactions, drug interactions etc. The use of a dedicated agent to attenuate the intubation stress response raises the issues of polypharmacy, drug interaction and hemodynamic disturbances produced by the said agent itself. Anaesthesiologists have for long tried to formulate a drug combination to intubate patients without coughing or bucking, in the absence of muscle relaxants. Keaveny JP \& Knell PJ were among the first workers to propose this concept of tracheal intubation without muscle relaxants. ${ }^{1}$

Though endotracheal intubation is often facilitated by a depolarizing muscle relaxant like suxamethonium during anaesthetic induction with short-acting hypnotics, serious side effects like increased intraocular pressure, severe postoperative myalgia, prolonged paralysis (scoline apnea), hypokalemia ${ }^{2}$ etc are often associated. Also, suxamethonium can precipitate life-threatening masseter spasm, malignant hyperthermia, cardiovascular effects like nodal/ junctional rhythms, severe bradycardia or ventricular dysrhythmias, a raised intracranial tension and increased intragastric pressure, in turn leading to a higher risk of acid aspiration syndrome. Routine use of suxamethonium for elective tracheal intubation has, in effect, ceased in the developed world. Tracheal intubation with non-depolarising relaxants may be associated with undesirable side effects such as prolonged neuromuscular blockade or even the inability to reverse it in an unanticipated difficult airway wherein airway management via mask ventilation or tracheal intubation is virtually impossible. Problems with neuromuscular blocking agents also include anaphylaxis with the highest incidence for succinylcholine and rocuronium and residual neuromuscular blockade.3,4 Anaphylaxis has even been reported with the relatively safer cisatracurium. ${ }^{5}$ Addition of lignocaine only produces suppression of cough reflex and adds little to the ease of laryngoscopy or passage of a tracheal tube between the vocal cords. ${ }^{6}$ For these reasons, a method of providing good intubating conditions rapidly, without muscle relaxants is being sought. Since the advent of short-acting potent opioids (good at suppressing airway reflexes) and newer intravenous anaesthetic agents, the possibility of intubation without muscle relaxant usage has been under evaluation.

In 1988, McKeating, Bali IM, Dundee JW compared IV thiopentone sodium $(4 \& 5 \mathrm{mg} / \mathrm{kg})$ and propofol $(2.5 \mathrm{mg} / \mathrm{kg})$ to assess suppression of airway reflexes and found out the latter to be a better hypnotic. ${ }^{7}$ Lateron Steven JB, Vescova MV, Harris KC \& others found that intubating conditions of IV etomidate with alfentanil were comparable to those with propofol and alfentanil and in fact, better than with IV thiopentone and alfentanil $^{8}$ since propofol has been reported to possess some characteristics that provide adequate intubation conditions in combination with fentanyl.9,10,11 Due to its profound suppression of airway reflexes, propofol is the most favoured agent in this regard.12,13,14 A study by Saarnivara L et al. only achieved a very low success rate of 16 $\%$ with IV $2 \mathrm{mg} / \mathrm{kg}$ propofol and $30 \mu \mathrm{g} / \mathrm{kg}$ alfentanil. However, Saarnivara L, Klemola VM could achieve $89 \%$ success in intubation with $2.5 \mathrm{mg} / \mathrm{kg}$ IV propofol with 30 $\mu \mathrm{g} / \mathrm{kg}$ alfentanil without muscle relaxants. ${ }^{15,16,17}$ Another study that compared tracheal intubation with $2.5 \mathrm{mg} / \mathrm{kg}$ IV propofol with and without $1.5 \mathrm{mg} / \mathrm{kg}$ lignocaine without using opioids or muscle relaxants found that the dose of IV propofol was sufficient to intubate the trachea without muscle relaxants and that adding $1.5 \mathrm{mg} / \mathrm{kg}$ IV lignocaine well attenuated the stress response to intubation. ${ }^{18,19,20}$ Most previous studies on tracheal intubation without muscle relaxants were conducted using propofol along with shortacting strong opioids like alfentanil, sufentanil and remifentanil. ${ }^{21,22,23}$ In view of these studies, higher doses of IV propofol ( $2.5 \mathrm{mg} / \mathrm{kg}$ and $3 \mathrm{mg} / \mathrm{kg}$ body weight) were selected in our study for better results.

The objective of the present study was to compare the hemodynamic changes occurring while intubating with 2 different doses of propofol.

\section{METHODS}

A prospective study comparing the heart rate, systolic blood pressure, diastolic and mean arterial blood pressure changed during intubation with varying doses of propofol without using muscle relaxants.

\section{Study Design}

The sample size was calculated using the formulae

$N=\frac{\left(\sigma 1^{2}+\sigma 2^{2}\right)\left(Z_{1-\alpha / 2}+Z_{1-\beta}\right)^{2}}{d^{2}}$

$d=\left|\mu_{1}-\mu_{2}\right|$

Where,

$\mathrm{n}$ - Sample size, $\sigma_{1}, \sigma_{2}-$ standard deviation of samples,

$\mu_{1}, \mu_{2}$ - means of samples, $\mathrm{d}$ - the difference between means,

$\mathrm{Z}_{1-\alpha / 2}$ - table value for significance level $\alpha$ \&

$\mathrm{Z}_{1-\beta}$ - table value corresponding to power $(1-\beta)$.

Considering heart rate and mean arterial pressure values at 1 minute after intubation from the reference study, 24 minimum sample size required (n) was calculated as $26 . \alpha=$ $0.05 ; \beta=$ type 2 error $(20 \%)$ and expected $13 \%$ drop-out rate, hence decided to take a sample size of 30 in each group.

After acquiring approval from our hospital ethics committee, ASA (PS) I and II patients, 20 - 65 years of either sex of Mallampatti Class I and II airway were included in the study. The study period was 18 months from April 2014 to September 2015. The body mass index for all selected subjects was $<28 \mathrm{~kg} / \mathrm{m}^{2}$. Pregnant patients, patients with documented difficult airways, those with unstable hemodynamics or allergy to propofol, those on beta-blocker medication and those with systemic illnesses like systemic 
hypertension, type 2 diabetes mellitus or bronchial asthma were all excluded. Patients were selected from the elective cases posted for abdominal, orthopaedic and ENT surgeries by consecutive sampling at Government Medical College, Thrissur and assessed pre-operatively. Written informed consent was obtained for the study.

A well-equipped operation room with central oxygen supply, working suctions, and anaesthetic work-stations with suitable vaporizers filled adequately and checked. Anaesthetic breathing circuits, assorted airways \& masks were kept ready. Emergency trolley with all necessary drugs and equipments, sufficient quantities of all drugs for GA induction, maintenance and reversal including opioids, benzodiazepines, succinylcholine, thiopentone sodium and propofol were also kept. Multichannel monitors with a defibrillator, blood pressure cuffs, suitable probes for pulse oximetry and capnography, intravenous cannulae of various gauges, central venous catheters, arterial and venous extension lines, Foley's urinary catheter and any other appropriate equipment required were kept ready in the OR. ASA Class I \& II patients undergoing elective abdominal, orthopaedics and ENT surgeries requiring general anaesthesia who met the inclusion criteria, were included in 2 groups of 30 each and weighed pre-operatively to accurately calculate drug dosages. An appropriate freeflowing intravenous line was established as soon as the patient was brought into the OR. On the table, a 5-lead ECG monitor, pulse oximeter and properly fixed BP cuff were attached to the patient. All patients were given $10 \mathrm{ml} / \mathrm{kg}$ Ringer Lactate IV infusion 10 minutes pre-induction and premedicated with IV glycopyrrolate $5 \mu \mathrm{g} / \mathrm{kg}$, IV ranitidine 0.3 $\mathrm{mg} / \mathrm{kg}$, IV ondansetron $100 \mu \mathrm{g} / \mathrm{kg}$, IV midazolam $0.02 \mathrm{mg} / \mathrm{kg}$ and IV fentanyl $2 \mu \mathrm{g} / \mathrm{kg}$ as slow bolus in the same order. After giving inj. fentanyl, patients were watched for apnoea, oxygen saturation and given $100 \%$ oxygen support by mask.

As it takes 5-7 minutes for the plasma concentration of fentanyl to equilibrate with that of the brain, 5 minutes were given following inj. fentanyl. Lignocaine $1.5 \mathrm{mg} / \mathrm{kg}$ as IV bolus followed by propofol in pre-calculated amounts 2.5 or 3 $\mathrm{mg} / \mathrm{kg}$ ), were given slowly intravenously over 10 seconds to each patient by the attendant anaesthesiologist as per his/her pre-anaesthetic assessment of the individual patient and grouped accordingly. IV propofol and lignocaine were administered in such a manner as to do laryngoscopy and intubation at 7 minutes after IV fentanyl. The attending anaesthesiologist was the final authority in deciding to include a particular patient in the low dose or high dose propofol group. The investigator (s)/ observer(s) had no say at all in this matter. Patients were watched for apnoea or fall in $\mathrm{O}_{2}$ saturation \& if required, ventilated bag-mask with 100 $\%$ oxygen was given.

Laryngoscopy and intubation were done 90 seconds after completion of propofol injection since good to excellent intubating conditions were obtained 90 seconds after a hypnotic dose of propofol as per various studies. Only one attempt at laryngoscopy and intubation was considered for the study. All male patients were intubated with Portex cuffed endotracheal tube ID $8.5 \mathrm{~mm}$ and female patients ID $7.5 \mathrm{~mm}$. Hemodynamic responses (Heart rate, Systolic Blood Pressure, Diastolic Blood Pressure \& Mean Arterial Pressure) were recorded at the following stages:- baseline value, just after giving propofol \& lignocaine, 1-minute post-intubation and then $3,5 \& 10$ minutes after intubation. If intubation was not possible, patients were given a muscle relaxant to facilitate intubation and excluded from the study. Following intubation, anaesthesia was maintained at the discretion of the attending anaesthesiologist.

Collected data were analyzed using SPSS software. Quantitative data were analyzed using mean +/- standard deviation and independent sample t-test. Qualitative data were analyzed using the proportions \& the chi-square test. The patients were grouped into 2 based on the dosage of propofol used - a low dose group, PL and a high dose group, $\mathrm{PH}$. Both groups were comparable with respect to age, sex and ASA physical status of patients. The maximum number of patients in both groups was in the 50- 64 years age range, followed by equal numbers in $20-34$ years \& $35-49$ years age bracket.

\section{RESULTS}

\begin{tabular}{|ccc|}
\hline Variables & Categories $(\mathbf{N}=\mathbf{6 0})$ & Number (\%) \\
& $20-34$ years & $18(30)$ \\
Age & $35-49$ years & $18(30)$ \\
& $50-64$ years & $22(36.7)$ \\
\multirow{3}{*}{ Gender } & $65-79$ years & $2(3.3)$ \\
& Male & $29(48.3)$ \\
\multirow{2}{*}{ Weight } & Female & $31(51.7)$ \\
& $40-49 \mathrm{~kg}$ & $16(26.7)$ \\
& $50-59 \mathrm{~kg}$ & $20(33.3)$ \\
\multirow{2}{*}{ ASA (Physical Status) } & $60-69 \mathrm{~kg}$ & $19(31.7)$ \\
\hline \multicolumn{2}{|c|}{ Table 1. Socio-Demographic Distribution in the Study Population } \\
\hline
\end{tabular}

\begin{tabular}{|c|c|c|c|c|c|c|}
\hline \multicolumn{7}{|c|}{ Baseline Values } \\
\hline & \multicolumn{2}{|c|}{ GROUP } & $\mathbf{N}$ & Mean & $\begin{array}{c}\text { Std. } \\
\text { Deviation }\end{array}$ & $\begin{array}{l}\text { Std. Error } \\
\text { Mean }\end{array}$ \\
\hline \multirow{2}{*}{ HR 1} & \multirow{2}{*}{ Dimension 1} & 1 & 30 & 80.53 & 9.224 & 1.684 \\
\hline & & 2 & 30 & 75.60 & 10.230 & 1.868 \\
\hline \multirow[b]{2}{*}{ SBP 1} & \multirow{2}{*}{ Dimension 1} & 1 & 30 & 138.10 & 9.700 & 1.771 \\
\hline & & 2 & 30 & 135.57 & 10.647 & 1.944 \\
\hline \multirow{2}{*}{ MAP 1} & \multirow{2}{*}{ Dimension 1} & 1 & 30 & 100.77 & 8.080 & 1.475 \\
\hline & & 2 & 30 & 100.93 & 7.192 & 1.313 \\
\hline \multirow{2}{*}{ DBP 1} & \multirow{2}{*}{ Dimension 1} & 1 & 30 & 82.23 & 8.799 & 1.607 \\
\hline & & 2 & 30 & 83.00 & 6.680 & 1.220 \\
\hline \multicolumn{7}{|c|}{ Just after giving iv propofol and lignocaine } \\
\hline \multirow{2}{*}{ HR 2} & \multirow{2}{*}{ Dimension 1} & 1 & 30 & 75.70 & 7.844 & 1.432 \\
\hline & & 2 & 30 & 70.40 & 9.751 & 1.780 \\
\hline \multirow{2}{*}{ SBP 2} & \multirow{2}{*}{ Dimension 1} & 1 & 30 & 119.23 & 6.694 & 1.222 \\
\hline & & 2 & 30 & 118.70 & 7.226 & 1.319 \\
\hline \multirow{2}{*}{ MAP 2} & \multirow{2}{*}{ Dimension 1} & 1 & 30 & 88.33 & 7.194 & 1.313 \\
\hline & & 2 & 30 & 88.87 & 5.853 & 1.069 \\
\hline \multirow{3}{*}{ DBP 2} & \multirow{3}{*}{ Dimension 1} & 1 & 30 & 72.97 & 8.319 & 1.519 \\
\hline & & 2 & 30 & 73.83 & 6.497 & 1.186 \\
\hline & & & ite $\mathrm{p}$ & intubati & & \\
\hline \multirow{2}{*}{ HR 3} & \multirow{2}{*}{ Dimension 1} & 1 & 30 & 83.60 & 9.522 & 1.738 \\
\hline & & 2 & 30 & 77.30 & 9.660 & 1.764 \\
\hline \multirow{2}{*}{ SBP 3} & \multirow{2}{*}{ Dimension 1} & 1 & 30 & 99.23 & 7.587 & 1.385 \\
\hline & & 2 & 30 & 98.23 & 6.553 & 1.196 \\
\hline \multirow{2}{*}{ MAP 3} & \multirow{2}{*}{ Dimension 1} & 1 & 30 & 72.27 & 5.085 & .928 \\
\hline & & 2 & 30 & 72.57 & 3.766 & .688 \\
\hline \multirow{2}{*}{ DBP 3} & \multirow{2}{*}{ Dimension 1} & 1 & 30 & 59.10 & 5.573 & 1.017 \\
\hline & & 2 & 30 & 59.80 & 5.075 & .926 \\
\hline \multicolumn{7}{|c|}{$\begin{array}{c}\text { Table 2. Hemodynamic Parameters - Baseline, after Giving IV } \\
\text { Propofol \& Lignocaine \& at 1-Minute Post Intubation [Group 1: PL } \\
\text { Group; Group 2: PH Group] }\end{array}$} \\
\hline
\end{tabular}




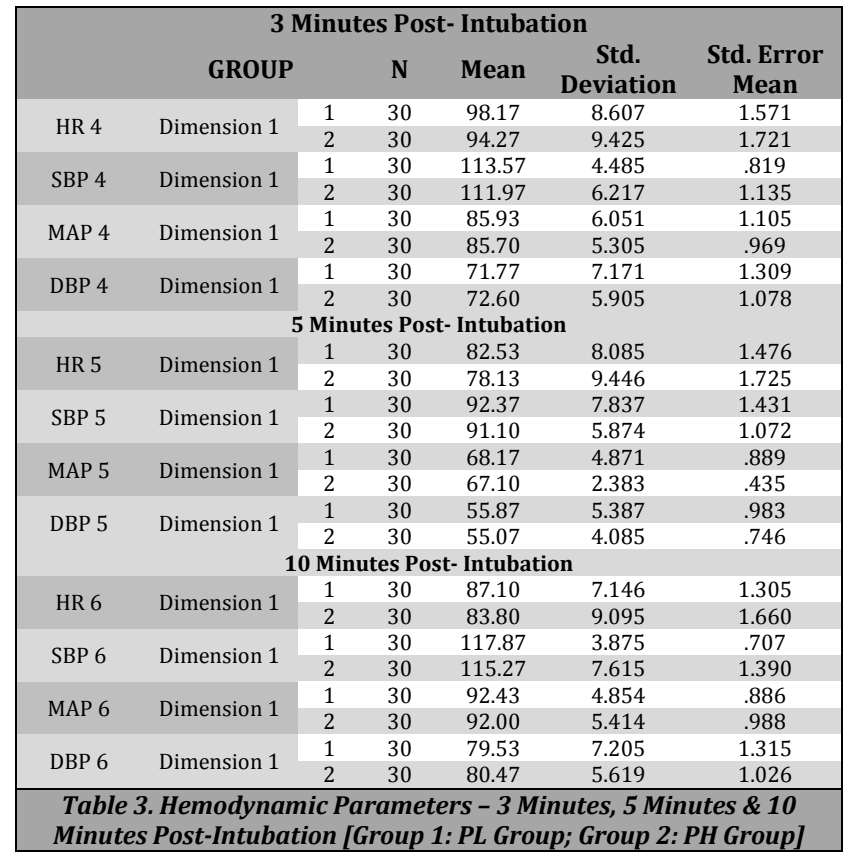

\begin{tabular}{|ccccc|}
\hline Parameters & Baseline & After IV Drugs & Mean Difference & P Value \\
HR & $80.5 \pm 9.2$ & $75.7 \pm 7.8$ & 4.93 & 0.06 \\
& $75.6 \pm 10.2$ & $70.4 \pm 9.8$ & 4.93 & 0.06 \\
SBP & $138.1 \pm 9.7$ & $119.2 \pm 6.7$ & 2.53 & 0.34 \\
& $135.6 \pm 10.6$ & $118.7 \pm 7.2$ & 2.53 & 0.34 \\
dBP & $82.2 \pm 8.8$ & $72.9 \pm 8.3$ & 0.77 & 0.70 \\
& $83.0 \pm 6.7$ & $73.8 \pm 6.5$ & 0.77 & 0.70 \\
MAP & $100.8 \pm 8.1$ & $88.3 \pm 7.2$ & 0.17 & 0.93 \\
& $100.9 \pm 7.2$ & $88.9 \pm 5.9$ & 0.17 & 0.93 \\
\hline Table 4. Comparison of Hemodynamic Parameters - Baseline \& after \\
\multicolumn{5}{|l}{ No statistically significant change was noted in HR or BP soon after giving IV Propofol } \\
\& lignocaine
\end{tabular}

\begin{tabular}{|c|c|c|c|c|}
\hline Parameters & Baseline & $\begin{array}{l}1 \text { Minute Post- } \\
\text { Intubation }\end{array}$ & $\begin{array}{c}\text { Mean } \\
\text { Difference }\end{array}$ & P Value \\
\hline \multirow{2}{*}{ HR } & $80.5 \pm 9.2$ & $83.6 \pm 9.5$ & 6.3 & 0.01 \\
\hline & $75.6 \pm 10.2$ & $77.3 \pm 9.7$ & 6.3 & 0.01 \\
\hline \multirow{2}{*}{ SBP } & $138.1 \pm 9.7$ & $99.2 \pm 7.6$ & 1.0 & 0.59 \\
\hline & $135.6 \pm 10.6$ & $98.2 \pm 6.6$ & 1.0 & 0.59 \\
\hline \multirow{2}{*}{ dBP } & $82.2 \pm 8.8$ & $59.1 \pm 5.6$ & 0.7 & 0.61 \\
\hline & $83.0 \pm 6.7$ & $59.8 \pm 5.1$ & 0.7 & 0.61 \\
\hline \multirow{2}{*}{ MAP } & $100.8 \pm 8.1$ & $72.3 \pm 5.1$ & 0.3 & 0.80 \\
\hline & $100.9 \pm 7.2$ & $72.6 \pm 3.8$ & 0.3 & 0.80 \\
\hline \multicolumn{5}{|c|}{$\begin{array}{c}\text { Table 5. Comparison of Hemodynamic Parameters - Baseline \& at } \\
\text { 1-Minute Post-Intubation }\end{array}$} \\
\hline
\end{tabular}

\begin{tabular}{|c|c|c|c|c|}
\hline Parameters & Baseline & $\begin{array}{l}1 \text { Minute Post- } \\
\text { Intubation }\end{array}$ & $\begin{array}{c}\text { Mean } \\
\text { Difference }\end{array}$ & P Value \\
\hline \multirow{2}{*}{ HR } & $80.5 \pm 9.2$ & $98.7 \pm 8.6$ & 3.9 & 0.10 \\
\hline & $75.6 \pm 10.2$ & $94.3 \pm 9.4$ & 3.9 & 0.10 \\
\hline \multirow{2}{*}{ SBP } & $138.1 \pm 9.7$ & $113.6 \pm 4.5$ & 1.6 & 0.26 \\
\hline & $135.6 \pm 10.6$ & $111.9 \pm 6.2$ & 1.6 & 0.26 \\
\hline \multirow[b]{2}{*}{ dBP } & $82.2 \pm 8.8$ & $71.7 \pm 7.2$ & 0.83 & 0.63 \\
\hline & $83.0 \pm 6.7$ & $72.6 \pm 5.9$ & 0.83 & 0.63 \\
\hline \multirow{2}{*}{ MAP } & $100.8 \pm 8.1$ & $85.9 \pm 6.1$ & 0.23 & 0.87 \\
\hline & $100.9 \pm 7.2$ & $85.7 \pm 5.3$ & 0.23 & 0.87 \\
\hline \multicolumn{5}{|c|}{$\begin{array}{l}\text { Table 6. Comparison of Hemodynamic Parameters - Baseline \& at } \\
\text { 3 Minutes Post-Intubation }\end{array}$} \\
\hline
\end{tabular}

\begin{tabular}{|c|c|c|c|c|}
\hline Parameters & Baseline & $\begin{array}{l}1 \text { Minute Post- } \\
\text { Intubation }\end{array}$ & $\begin{array}{c}\text { Mean } \\
\text { Difference }\end{array}$ & P Value \\
\hline \multirow{2}{*}{ HR } & $80.5 \pm 9.2$ & $82.5 \pm 8.1$ & 4.4 & 0.06 \\
\hline & $75.6 \pm 10.2$ & $78.1 \pm 9.4$ & 4.4 & 0.06 \\
\hline \multirow[b]{2}{*}{ SBP } & $138.1 \pm 9.7$ & $92.4 \pm 7.8$ & 1.27 & 0.48 \\
\hline & $135.6 \pm 10.6$ & $91.1 \pm 5.9$ & 1.27 & 0.48 \\
\hline \multirow{2}{*}{ dBP } & $82.2 \pm 8.8$ & $55.9 \pm 5.4$ & 0.8 & 0.52 \\
\hline & $83.0 \pm 6.7$ & $55.1 \pm 4.1$ & 0.8 & 0.52 \\
\hline \multirow{2}{*}{ MAP } & $100.8 \pm 8.1$ & $68.2 \pm 4.9$ & 1.1 & 0.29 \\
\hline & $100.9 \pm 7.2$ & $67.1 \pm 2.4$ & 1.1 & 0.29 \\
\hline \multicolumn{5}{|c|}{$\begin{array}{c}\text { Table 7. Comparison of Hemodynamic Parameters - Baseline \& at } \\
5 \text { Minutes Post-Intubation }\end{array}$} \\
\hline
\end{tabular}

\begin{tabular}{|ccccc|}
\hline Parameters & Baseline & $\begin{array}{c}\text { 1 Minute Post- } \\
\text { Intubation }\end{array}$ & $\begin{array}{c}\text { Mean } \\
\text { Difference }\end{array}$ & P Value \\
& $80.5 \pm 9.2$ & $87.1 \pm 1.3$ & 3.3 & 0.12 \\
HR & $75.6 \pm 10.2$ & $83.8 \pm 1.7$ & 3.3 & 0.12 \\
& $138.1 \pm 9.7$ & $117.9 \pm 3.9$ & 2.6 & 0.10 \\
SBP & $135.6 \pm 10.6$ & $115.3 \pm 7.6$ & 2.6 & 0.10 \\
& $82.2 \pm 8.8$ & $79.5 \pm 7.2$ & 0.93 & 0.58 \\
dBP & $83.0 \pm 6.7$ & $80.5 \pm 5.6$ & 0.93 & 0.58 \\
& $100.8 \pm 8.1$ & $92.4 \pm 4.9$ & 0.43 & 0.75 \\
MAP & $100.9 \pm 7.2$ & $92.0 \pm 5.4$ & 0.43 & 0.75 \\
\hline Table 8 Comparison of Hemodynamic Parameters - Baseline \& at 10
\end{tabular}

Table 8. Comparison of Hemodynamic Parameters - Baseline \& at 10 Minutes Post-Intubation

No statistically significant heart rate or BP changes were noted at 10 minutes postintubation.

Comparison of the hemodynamic parameters revealed no statistically significant differences between the low dose propofol (PL) and high dose propofol (PH) groups. Even though heart rate was found to increase at 3 to 10 minutes post-intubation, very similar changes were found in both groups. Statistically, significant change was seen only in heart rate values at 1-minute post-intubation. Also, the blood pressure values showed similar trends of initial decrease (albeit statistically insignificant) followed by a subsequent increase at 1 minute to 10 minutes post-intubation. In premedicated healthy patients with favourable airway anatomy, tracheal intubation was comfortably achieved with a combination of IV $2 \mu \mathrm{g} / \mathrm{kg}$ fentanyl and IV $2.5 \mathrm{mg} / \mathrm{kg}$ or 3 $\mathrm{mg} / \mathrm{kg}$ propofol. This technique is valued in select patients as muscle relaxant administration is associated with quite a few undesirable effects. No significant incidents of desaturation or arrhythmias occurred in any patient during the course of this study. No statistically significant difference in heart rate, systolic blood pressure, mean arterial pressure or diastolic blood pressure between PL \& PH groups was noted before intervention. No statistically significant difference seen in hemodynamic values in PL \& PH groups just after IV propofol and lignocaine administration at $1,3,5$ or 10 minutes postintubation.

\section{DISCUSSION}

A method for providing good intubation conditions safely, effectively and rapidly without the use of muscle relaxants has been long sought after. This is primarily due to the sideeffect profile of the commonly used non-depolarizing and depolarizing muscle relaxants. ${ }^{25,26}$ The present study was thus conducted in 60 ASA (PS) I and II patients included in two groups of 30 each; the first group being PL - Propofol lower dose and the second group, PH - Propofol higher dose who were posted to undergo general surgical, orthopaedic or ENT procedures at Government Medical College, Thrissur to verify the ease of intubation with 2 different induction doses of propofol without the use of any muscle relaxant and to compare the hemodynamic effects therein. Consecutive sampling was used in this study. Group PL received 2.5 $\mathrm{mg} / \mathrm{kg}$ IV propofol and $\mathrm{PH}$ group received $3 \mathrm{mg} / \mathrm{kg}$ IV propofol. In addition, both the groups were given $2 \mu \mathrm{g} / \mathrm{kg}$ IV fentanyl as pre-medication 7 minutes prior to intubation. Heart rates, systolic blood pressure, mean arterial pressure, and diastolic blood pressures were recorded at the onset (baseline value) of the procedure, just after IV propofol and lignocaine $1.5 \mathrm{mg} / \mathrm{kg}$ IV and at 1 minute, 3 minutes, 5 minutes and 10 minutes post-intubation. Comparing the hemodynamic parameters revealed no differences of 
statistical significance between the low dose (PL) and high dose propofol $(\mathrm{PH})$ groups. The heart rate was found to increase at 3 to 10 minutes post-intubation similarly, in both groups. Also, the systolic blood pressure, mean arterial pressure and diastolic blood pressure values initially decreased and then increased, post-intubation. No patient receiving IV fentanyl in either group developed chest wall rigidity or any other adverse effects. ${ }^{27}$ In no patient was mask ventilation difficult or impossible. According to the evidences by animal and human studies, benzodiazepines prevent / attenuate fentanyl-induced muscle rigidity. Administration of IV midazolam as premedication in our study may have thus proved useful. The relative hypotension seen in the study was associated with good peripheral perfusion as evidenced by continuing digital pulse oximeter readings and was transient. Intubation of the trachea was always followed by a fall in blood pressure which may not be appropriate for all groups of patients, especially elderly or hypovolemic patients or in others with some form of cerebrovascular or cardiovascular disease. The state of the patient post-intubation is of concern to most anaesthesiologists. For up to ten minutes postintubation, most of the patients exhibited no persistent coughing or purposeful movements. However, additional drugs including nitrous oxide, isoflurane or other inhalants, propofol or dexmedetomidine may be required to reliably prevent coughing or movement in the subsequent period, in addition to non-depolarizing muscle relaxants, while following this technique for tracheal intubation. A waiting period of around 7 minutes is crucial after administering IV fentanyl as the peak action of fentanyl occurs around this period as per several earlier studies. ${ }^{28}$ IV fentanyl, in addition to adequate doses of propofol, was crucial in providing sufficient intubating conditions in this study. ${ }^{29}$ In premedicated healthy patients with favourable airway anatomy, tracheal intubation can be comfortably accomplished using a combination of $2 \mu \mathrm{g} / \mathrm{kg}$ fentanyl and $2.5 \mathrm{mg} / \mathrm{kg}$ or $3 \mathrm{mg} / \mathrm{kg}$ IV propofol - the lower dose particularly useful in patients with optimized comorbidities or mild hypovolemia while the higher dose may be useful in healthy adults with more muscle mass. ${ }^{30}$

\section{CONCLUSIONS}

Patients in group PL (propofol low dose) and PH (propofol high dose) had adequate and comparable intubating conditions with similar changes in hemodynamic parameters like heart rate, systolic blood pressure, mean arterial pressure and diastolic blood pressure during intubation through 1, 3, 5 and 10 minutes afterwards. There was no significant statistical difference between groups PL and PH regarding changes in heart rate \& blood pressure at similar intervals. After intubation, though both groups of patients saw a decrease in blood pressure values along with a reflex increase in heart rate at 1 minute to 5 minutes postintubation, it returned to near-baseline values by 10 minutes post-intubation. None of the changes noted was clinically detrimental to the patients. It can thus be safely concluded that both doses of IV propofol used in the study with prior administration of IV fentanyl, 7 minutes before intubation, provide good intubation conditions without the use of muscle relaxants. The lower dose propofol used in the PL group may be more useful in elderly or mildly hypovolemic patient groups while the higher dose used in the PH group is helpful in the healthy adults with a higher muscle mass in clinical situations where muscle relaxant usage is to be restricted or altogether avoided.

\section{Limitations}

They include varied drug doses dependent on patients' weight which can have some effect on final results. Also, as laryngoscopy and intubation were performed by different anaesthesiologists, the degree of difficulty in intubation could not be accurately compared and assessed. As only a single attempt at intubation was permitted in the study, many faulty laryngoscopes and intubation techniques may have counted out as difficult airways, being excluded from the study altogether.

Data sharing statement provided by the authors is available with the full text of this article at jemds.com.

Financial or other competing interests: None.

Disclosure forms provided by the authors are available with the full text of this article at jemds.com.

\section{REFERENCES}

[1] Keaveny JP, Knell PJ. Intubation under induction doses of propofol. Anaesthesia 1988;43 Suppl:80-1.

[2] Scheller MS, Zornow MH, Saidman LJ. Tracheal intubation without the use of muscle relaxants: a technique using propofol and varying doses of alfentanil. Anesth Analg 1992;75(5):788-93.

[3] Laxenaire MC. Substances responsible for preanesthetic anaphylactic shock. A third French multicenter study (1992-94). Ann Fr Anesth Reanim 1996;15(8):1211-8.

[4] Barthelet Y, Ryckwaert Y, Plasse C, et al. Severe anaphylactic reactions after administration of rocuronium. Ann Fr Anesth Reanim 1999;18(8):896900.

[5] Yoon Y, Lee B, Seo HS, et al. Anaphylactic reactions after cisatracurium administration in two patients - a report of two cases. Korean J Anesthesiol 2013;65(2):147-50.

[6] Prakash S, Arora D, Prakash S, et al. A combination of fentanyl-midazolam-propofol provides better intubating conditions than fentanyl-lignocaine-propofol in the absence of neuromuscular blocking agents. Acta Anaesthesiol Scand 2006;50(8):999-1004.

[7] McKeating K, Bali IM, Dundee JW. The effects of thiopentone and propofol on upper airway integrity. Anaesthesia 1988;43(8):638-40.

[8] Stevens JB, Vescova MV, Harris KC, et al. Tracheal intubation using alfentanil and no muscle relaxant: is the choice of hypnotic important? Anesth Analg 1997;84(6):1222-6.

[9] Erhan E, Ugur G, Gunusen I, et al. Propofol-not thiopental or etomidate-with remifentanil provides adequate intubating conditions in the absence of neuromuscular blockade. Can J Anesth 2003;50(2):108-15.

[10] Taha S, Siddik-Sayyid S, Alameddine M, et al. Propofol is superior to thiopental for intubation without muscle relaxants. Can J Anaesth 2005;52(3):249-53. 
[11] Streibel HW, HÖlzl M, Rieger A, et al. Endotracheal intubation with propofol and fentanyl. Anaesthetist 1995;44(12):809-17.

[12] Grange S, Suresh D, Meikle R, et al. Intubation with propofol: evaluation of pretreatment with alfentanil or lignocaine. Eur J Anaesthesiol 1993;10(1):9-12.

[13] Srivastava U, Kumar A, Gandhi NK, et al. Comparison of Propofol and fentanyl with thiopentone and suxamethonium for tracheal intubation in children. Indian J Anaesth 2001;45:263-6.

[14] Hovorka J, Honkavaara P, Korttila K. Tracheal intubation after induction of anesthesia with thiopentone or propofol without muscle relaxants. Acta Anaesthesiol Scand 1991;35(4):326-8.

[15] Saarnivara L, Klemola UM. Injection pain, intubation conditions and cardiovascular changes following induction of anesthesia with propofol alone or in combination with alfentanil. Acta Anaesthesiol Scand 1991;35(1):19-23.

[16] Davidson JA, Gillespie JA. Tracheal intubation after induction of anesthesia with propofol, alfentanil and i.v. lignocaine. Br J Anaesth 1993;70(2):163-6.

[17] Woods AW, Grant S, Harten J, et al. Tracheal intubating conditions after induction with propofol, lignocaine and remifentanil. Eur J Anaesthesiol 1988;15(6):714-8.

[18] Mullholand D, Carlisle RJ. Intubation with propofol augmented with intravenous lignocaine. Anaesthesia 1991;46(4):312-3.

[19] Gore MS, Harnagale KD. Evaluation of intubating conditions with varying doses of propofol without muscle relaxants. J Anaesthesiol Clin Pharmacol 2011;27(1):27-30.

[20] Gupta A, Kaur R, Malhotra R, et al. Comparative evaluation of different doses of propofol preceded by fentanyl on intubating conditions and pressor response during tracheal intubation without muscle relaxants. Paediatr Anaesth 2006;16(4):399-405.

[21] Alcock R, Peachey T, Lynch M, et al. Comparison of alfentanil with suxamethonium in facilitating nasotracheal intubation in day-case anesthesia. $\mathrm{Br} \mathrm{J}$ Anaesth 1993;70(1):34-7.

[22] Wei LX, Deng XM, Wang L, et al. Induction of tracheal intubation without muscle relxant by target-controlled infusion of propofol combined with remifentanil in children. Zhongguo Yi Xue Ke Xue Yuan Xue Bao 2011;33(4):440-4.

[23] Goyagi T, Yoshimoto M. Comparison of hemodynamic response associated with tracheal intubation under various induction doses of remifentanil and propofol. Open J Aesthesiol 2012;2(4):154-60.

[24] Grundmann U, Uth M, Eichner A, et al. Total intravenous anaesthesia with propofol and remifentanil in paediatric patients: a comparison with a desflurane-nitrous oxide inhalation anaesthesia. Acta Anesthesiol Scand 1998;42(7):845-50.

[25] Naguib M, Samarkandi A, Riad W, et al. Optimal dose of succinylcholine revisited. Anesthesiology 2003;99(5):1045-9.

[26] Schepens T, Cammu G. Neuromuscular blockade: what was, is and will be. Acta Anaesthseiol Belg 2014;65(4):151-9.

[27] Sawano Y, Miyazaki M, Shimada H, et al. Optimal fentanyl dosage for attenuating systemic hemodynamic changes, hormone release and cardiac output changes during the induction of anesthesia in patients with and without hypertension: a prospective, randomized, doubleblinded study. J Anesth 2013;27(4):505-11.

[28] Chang DJ, Kweon TD, Nam SB, et al. Effects of fentanyl pretreatment on the QTc interval during propofol induction. Anaesthesia 2008;63(10):1056-60.

[29] Kwon MA, Kim SK, Jeon DG, et al. The effect of additional propofol on intubation conditions. J Clin Anesth 2010;22(8):603-7.

[30] Shaikh SI, Bellagali VP. Tracheal intubation without neuromuscular block in children. Indian J Anaesth 2010;54(1):29-34. 